\title{
The imbibing idiot bias: Consuming alcohol can be hazardous to your (perceived) intelligence ${ }^{\hbar}$
}

\author{
Scott I. Rick ${ }^{a, *}$, Maurice E. Schweitzer ${ }^{b}$ \\ ${ }^{\text {a }}$ Ross School of Business, University of Michigan, USA \\ ${ }^{\mathrm{b}}$ The Wharton School, University of Pennsylvania, USA
}

Received 22 September 2011; received in revised form 2 June 2012; accepted 12 June 2012 Available online 19 June 2012

\begin{abstract}
Alcohol consumption and cognitive impairment frequently co-occur. We propose that the relationship is so familiar that exposure to alcohol cues primes expectations of cognitive impairment. Across five studies, we find that in the absence of any evidence of reduced cognitive performance, people who hold an alcoholic beverage are perceived to be less intelligent than those who do not, a mistake we term the imbibing idiot bias. In fact, merely priming observers with alcohol cues causes them to judge targets who hold no beverage at all as less intelligent. The bias is not driven by a belief that less intelligent people are more likely to consume alcohol. We find that the bias may be costly in professional settings. Job candidates who ordered wine during an interview held over dinner were viewed as less intelligent and less hireable than candidates who ordered soda. However, prospective candidates believe that ordering wine rather than soda will help them appear more intelligent.
\end{abstract}

(C) 2012 Society for Consumer Psychology. Published by Elsevier Inc. All rights reserved.

Keywords: Impression formation; Impression management; Conceptual consumption; Person perception; Alcohol

O God, that men should put an enemy in their mouths to steal away their brains! - Cassio, Othello

\section{Introduction}

What we consume influences the impressions we make on others (Berger \& Heath, 2007; Gosling, 2008). In this research, we examine how consuming alcohol influences how we are perceived. Of course, consuming alcohol may influence how we are viewed by changing our behavior. For example, after

\footnotetext{
is We thank the Editor, the Associate Editor, and three anonymous reviewers for helpful feedback. We thank Taylor Begley, Stephanie Carpenter, Jordan Etkin, Alexander Leeds, Stanley Liu, Jonathan Moore, Beatriz Pereira, George Rausch, Laura Rees, Nicole Ruedy, Jason Stornelli, and the Wharton Behavioral Lab for research assistance.

* Corresponding author at: University of Michigan, 701 Tappan Street, R5486, Ann Arbor, MI 48109, USA.

E-mail address: srick@umich.edu (S.I. Rick).
}

a few drinks, we may say or do something boorish, causing others to view us as unintelligent. However, separate from any influence on behavior, how does merely choosing to consume alcohol influence how we are perceived?

Viewing someone who holds an alcoholic beverage may bring to mind a variety of expectations. We propose that alcohol is particularly likely to be associated with expectations of cognitive impairment. Alcohol consumption and cognitive impairment frequently co-occur (e.g., Steele \& Josephs, 1990), and the association between alcohol and cognitive impairment has been illustrated for millennia in literature, cinema, bars, and homes. In fact, the association between alcohol and cognitive impairment is one of the most enduring and ubiquitous associations for any food or beverage over time and across cultures.

Critically, expectations of cognitive impairment may act as a lens through which observers view individuals holding an alcoholic beverage (e.g., Srull \& Wyer, 1979). These expectations may cause observers to judge individuals as less intelligent when they hold an alcoholic beverage than when they do not. In this 
paper, we examine whether observers make this mistake, which we term the "imbibing idiot bias."

\section{Overview of the present research}

We conducted five studies to investigate how alcohol cues influence perceptions of intelligence. In Study 1, we demonstrate that merely priming observers (participants) with alcohol cues causes them to evaluate ambiguous targets (holding no beverage) as less intelligent.

Study 2 examines the imbibing idiot bias in a more naturalistic context. We find that observers judge targets in photographs as less intelligent when they are holding an alcoholic beverage than when they are not.

In Study 3, we examine an alternative explanation for our findings in Study 2. Observers may believe that less intelligent people are more likely to consume alcohol (a self-selection account). In actuality, moderate drinkers outperform non-drinkers across a range of cognitive tests (Elias, Elias, D'Agostino, Silbershatz, \& Wolf, 1999; Stampfer, Kang, Chen, Cherry, \& Grodstein, 2005). Nevertheless, observers may (wrongly) believe that alcohol consumption is diagnostic of low intelligence. We examine this self-selection account in Study 3.

Study 4 explores whether the bias persists when observers have evidence diagnostic of intelligence. In this study, observers view and then evaluate targets who make a persuasive speech while holding a beverage that is either alcoholic or non-alcoholic.

Finally, Study 5 examines potential costs of the bias. Given that quickly-formed perceptions of intelligence can be influential (e.g., Todorov, Mandisodza, Goren, \& Hall, 2005), and that business is often conducted in settings involving alcohol (Galinsky \& Schweitzer, 2007; Schweitzer \& Kerr, 2000), an imbibing idiot bias could prove costly. Study 5 examines whether ordering wine at an interview held over dinner diminishes perceptions of candidates' intelligence and hireability.

\section{Study 1}

In Study 1, we establish the imbibing idiot bias. Specifically, we primed individuals with either neutral concepts or the concept of alcohol, and then had participants rate the intelligence of a target (holding no beverage at all).

\section{Method}

We recruited 176 adults $(63 \%$ female, mean age $=34)$ via Amazon Mechanical Turk (MTurk), a recruitment platform validated by Paolacci, Chandler, and Ipeirotis (2010). We described the experiment to participants as consisting of two separate studies.

To manipulate whether participants were primed with the concept of alcohol, we adapted a method validated by Bartholow and Heinz (2006). Specifically, we informed participants that in "Study 1" they would evaluate print advertisements. Participants were either randomly assigned to view six neutral ads (Carnation evaporated milk, Ritz crackers, Coca-Cola soda, Kraft mayonnaise, Morton salt, Viva paper towels) or six alcohol-related ads (Carling beer, Coors beer, Guinness beer, Michelob beer, Stolichnaya vodka, Hofbrau beer). To build credibility in our cover story, we asked participants to rate the visual appeal and likely effectiveness of each ad. The ads we selected featured the product itself, and no people.

Next, we described "Study 2" as a pre-test of a photograph we planned to use in future studies. Participants viewed a photograph of a male actor sitting at a table. The "target" in this experiment held no beverage (see Appendix A), and the photograph of the target was the same across conditions. We asked participants two questions about the target. Specifically, participants rated the extent to which the target was "intelligent" and "likeable" on 1-7 scales, where $1=$ not at all and $7=$ very much.

Results

The results provide evidence of an imbibing idiot bias. Participants rated the target as less intelligent following the alcohol prime $(M=4.44, S D=1.18)$ than they did following the neutral prime $(M=4.77, S D=1.04 ; t(174)=1.98, p<.05, d=.30)$. We found no difference in likeability ratings across the alcohol and neutral prime conditions $(M=4.54, S D=1.26$ vs. $M=4.57$, $S D=1.24 ; t(174)<1)$, suggesting that alcohol cues do not produce globally negative evaluations.

\section{Study 2}

Study 2 examines the bias in a more naturalistic context. Specifically, we examine whether targets who hold an alcoholic beverage are viewed as less intelligent than targets who do not.

\section{Method}

We recruited 109 participants $(53 \%$ female, mean age $=35)$ via MTurk. The study featured a within-subject design. Participants viewed a series of four photographs of different female targets. Each series included a photograph of an actor holding a bottle of beer, and a photograph of a different actor holding a glass of water. We counterbalanced whether the actor holding a bottle of beer appeared first and the actor holding a glass of water appeared fourth, or vice versa. We also counterbalanced which actor was shown first. Thus, each series of photographs included two of the four photographs in Appendix A. The second and third photographs in the series were filler photographs of other females, held constant across participants. Participants were asked "To what extent do you think this person is intelligent?" and "To what extent do you think this person is likeable?" Perceived intelligence and likeability were rated on 1-7 scales, where $1=$ not at all and $7=$ very much.

\section{Results}

We focused our analyses on participants' ratings of the first and fourth photographs in the series. Participants rated actors as significantly less intelligent $(M=4.47, S D=1.43$ vs. $M=5.11$, $S D=1.02 ; t(108)=4.14, p<.0001$, paired $t$-test, $d=.52)$, but no 
less likeable $(M=4.36, S D=1.29$ vs. $M=4.42, S D=1.25$; $t(108)<1$, paired $t$-test) when holding an alcoholic beverage than when holding a glass of water.

The results suggest that holding an alcoholic beverage can selectively reduce perceived intelligence. In a supplemental study with a male target, we found that the bias extends to wine (Appendix C).

\section{Study 3}

We propose that alcohol cues prime expectations of cognitive impairment that bias subsequent perceptions. However, an alternative explanation for Study 2 is that observers believe that less intelligent people are most likely to consume alcohol (a self-selection account). Although the bias can be observed in the absence of alcohol consumption (Study 1), we now investigate the self-selection account directly.

\section{Method}

We recruited 101 participants $(45 \%$ female, mean age $=33)$ via MTurk. We asked participants, "Who do you think is more likely to drink alcoholic beverages on a regular basis: highly intelligent people or less intelligent people?" Participants could select one of three statements: "Highly intelligent people are more likely to drink alcoholic beverages on a regular basis," "Less intelligent people are more likely to drink alcoholic beverages on a regular basis," or "Highly intelligent people and less intelligent people are about equally likely to drink alcoholic beverages on a regular basis."

Results

A significant majority of participants $(60 \%)$ indicated that highly intelligent people and less intelligent people are about equally likely to drink alcoholic beverages on a regular basis $(p<.05$, sign test). The remaining participants were split between thinking that routine alcohol consumption is diagnostic of low intelligence $(30 \%)$ or that routine alcohol consumption is diagnostic of high intelligence $(10 \%)$.

These results suggest that most people $(70 \%)$ do not believe that consuming alcohol is diagnostic of low intelligence. This finding, as well as those from Study 1, suggest that a self-selection account cannot explain the imbibing idiot bias.

\section{Study 4}

In Study 4, we extend our investigation to examine whether the imbibing idiot bias persists when observers have evidence diagnostic of the target's intelligence. Targets in this study deliver a persuasive speech while holding a beverage that is either alcoholic or non-alcoholic. If the bias persists in this context, it may have broad impact. In particular, individuals may have difficulty recovering from the impression they create by holding an alcoholic beverage.

We also provide another test of the self-selection account. Specifically, we manipulate whether the target actively chooses an alcoholic beverage or merely accepts one after someone else chose it for him. If the bias is driven by beliefs about what types of people choose to consume alcohol, we should observe stronger evidence for the bias when the target actively chooses alcohol.

\section{Method}

We recruited 427 undergraduates (57\% female) from the Wharton School. We informed participants that we recently approached several graduating seniors at a restaurant and asked them to consider whether the university should require comprehensive exams. The seniors were presumably given a fact sheet about comprehensive exams and then asked to state their own opinion on video. We told participants that we would randomly select one of the videos and ask them to evaluate the speaker.

We told participants that, to thank each speaker, we paid them $\$ 5$ and bought them a drink. We varied who selected the drink (the speaker selected his own drink or the experimenter bought the same drink for every speaker), as well as the type of drink (soda or beer). In the Forced Choice condition, we told participants:

We bought each person a [Coke/beer]. We approached this student before he had ordered a beverage and ordered the [Coke/ beer] for him, which we paid for.

In the Free Choice condition, we told participants:

We bought each person a drink of their choice. We approached this student after he had ordered a [Coke/beer], which we paid for.

The experiment thus employed a 2 (Speaker Agency: Free Choice or Forced Choice) $\times 2$ (Drink Type: soda or beer) between-subjects design.

Participants then viewed a one-minute video of a male speaker making two arguments in favor of comprehensive exams, adapted from Norton, Dunn, Carney, and Ariely (2012). While making his arguments, the speaker held a can of soda or a bottle of beer (Appendix A). While talking, the speaker took two sips of the beverage. (Full stimuli are available from the authors.)

Following the video, we asked participants to indicate the extent to which they found the speaker's arguments persuasive, convincing, and thoughtful, as well as the extent to which they were "moved" by the speaker's arguments and the extent to which they were able to take the speaker seriously. Participants responded on 1-7 scales, with higher responses indicating greater quality. We averaged the five responses to form a speaker persuasiveness index $(\alpha=.88)$.

We then asked participants to evaluate the overall intelligence of the speaker. Specifically, we asked participants to indicate the extent to which they thought the speaker was "intelligent," "scholarly," and "intellectual." Participants responded on 1-7 scales, with higher responses indicating greater quality. We averaged the three responses to form a speaker intelligence index $(\alpha=.95){ }^{1}$

\footnotetext{
${ }^{1}$ Confirmatory factor analyses confirmed that the persuasiveness and intelligence items captured distinct constructs.
} 


\section{Attention check}

Finally, we asked participants to recall what the speaker was drinking and to indicate who had selected the speaker's drink: the Speaker, the Scientist conducting the study, or Don't Recall.

Nearly all participants $(99.5 \%)$ correctly recalled what the speaker was drinking $(p<.0001$, sign test). A significant majority $(75 \%)$ also correctly recalled who selected the drink $(p<.0001$, sign test).

\section{Results}

We focused our analyses on the 319 participants who passed both Attention checks. (We observe the same pattern if we include all participants.) We conducted a factorial ANOVA treating the speaker persuasiveness index as the dependent variable, and Speaker Agency and Drink Type as independent variables. We found a significant main effect of Drink Type $(F(1,315)=4.99, p<.05)$. Specifically, the speaker's arguments were viewed as significantly less persuasive when the speaker was drinking beer $(M=2.86, S D=1.24)$ than when the speaker was drinking soda $(M=3.21, S D=1.28 ; t(317)=2.46, p=.014$, $d=.28$ ). We found no main effect of Speaker Agency and no interaction (both $F_{\mathrm{S}}<1$ ).

We then conducted a factorial ANOVA treating the speaker intelligence index as the dependent variable, and Speaker Agency and Drink Type as independent variables. We found a significant main effect of Drink Type $(F(1,315)=$ $6.69, p<.05)$. Specifically, the speaker was viewed as significantly less intelligent when the speaker was drinking beer $(M=3.20, S D=1.36)$ than when the speaker was drinking soda $(M=3.64, S D=1.35 ; t(317)=2.93, p<.01, d=.32)$. We found no main effect of Speaker Agency and no interaction (both $p s>.20$ ).

To examine whether speaker persuasiveness mediated the effect of drinking beer on speaker intelligence, we performed a bootstrapping analysis (5000 iterations; Preacher \& Hayes, 2004). The analysis revealed a significant indirect effect of drinking beer on speaker intelligence, as indicated by a $95 \%$ confidence interval for the indirect effect that did not contain zero (range: -.45 to -.05 ).

These results suggest that the imbibing idiot bias persists when evidence diagnostic of intelligence is available. Future research could further explore this issue by examining whether holding an alcoholic beverage can reverse initial positive impressions of a target's intelligence (e.g., by delivering an alcoholic beverage to the speaker toward the end of the video, rather than having the speaker holding an alcoholic beverage throughout).

The results are also consistent with our proposed process: alcohol cues prime observers to expect cognitive impairment, which in turn leads to perceptions of diminished intelligence. In this setting, judgments of the speaker's persuasiveness may serve as a proxy for the extent to which the speaker is viewed as cognitively impaired. Future research should extend our investigation and more directly investigate this process.
Finally, because the bias persists when the target did not actively choose to consume alcohol, the results further suggest that self-selection cannot explain the imbibing idiot bias.

\section{Study $5 \mathrm{~A}$}

In Study 5A, we explore potential consequences of the imbibing idiot bias. When business is conducted outside the office, alcohol consumption is common. In this study, we examine whether ordering wine at an interview held over dinner diminishes perceptions of candidates' intelligence. In our interview context (an interview for a management position), perceived intelligence should influence the hiring decision. Thus, in addition to measuring perceptions of intelligence, we also measure perceptions of hireability.

\section{Method}

We recruited participants from a paid panel of managers maintained by Qualtrics. Our sample consisted of 300 "mid-level managers" (50\% female; mean age $=46)$, whose occupational role was either Director, Manager, or Assistant Manager. Participants had an average of 11.4 years of managerial experience.

We informed participants that they would see a portion of an interview between a manager and a job candidate, held over dinner. Participants then read the interview dialogue, which was accompanied by photographs (Appendices A and B). Early in the interview, the manager ordered wine (a glass of Merlot), and then the candidate ordered a drink. We varied the candidate's drink choice (Coke or a glass of Merlot). Thus, the experiment had two conditions.

Drinks were then delivered, and the interview concluded with a discussion of the candidate's strengths and experience. Aside from drink orders, the interview dialogue was held constant across conditions.

\section{Dependent variables}

Following the interview, we assessed the candidate's hireability by asking participants "Do you think the candidate should be hired?" and "If the manager asked your opinion right now, how likely is it that you would recommend the candidate for the job?" Responses were made on 1-7 scales, with higher responses indicating greater hireability. The items correlated highly $(r(298)=.91)$ and were averaged to form a hireability index.

Then, to assess the candidate's intelligence, we asked participants to indicate the extent to which the candidate was intelligent, scholarly, and intellectual on 1-7 scales, where $1=$ not at all and $7=$ very much. We averaged the three items to form an intelligence index $(\alpha=.93)$.

\section{Results}

Participants rated candidates as significantly less hireable when they ordered wine $(M=4.09, S D=1.29)$ than when they ordered soda $(M=4.64, S D=1.34 ; t(298)=3.59, p<.001, d=$ $.42)$. Participants also rated candidates as significantly less 
intelligent when they ordered wine $(M=4.42, S D=1.10)$ than when they ordered soda $(M=4.84, S D=1.04 ; t(298)=3.39$, $p<.001, d=.39$ ).

To examine whether perceived intelligence mediated the effect of ordering wine on perceived hireability, we performed a bootstrapping analysis (5000 iterations). The analysis revealed a significant indirect effect of ordering wine on perceived hireability, as indicated by a $95 \%$ confidence interval for the indirect effect that did not contain zero (range: -.57 to -.16 ).

These results suggest that the imbibing idiot bias may be costly in professional settings involving alcohol. Job candidates who order wine run the risk of being perceived as less intelligent and, consequently, less hireable.

\section{Study 5B}

The imbibing idiot bias can only cause harm if candidates choose to order alcohol. Thus, in Study 5B, we explore intuitions job candidates have about ordering alcohol during a recruiting dinner.

\section{Method}

We recruited 44 Executive MBA students (16\% female, mean age $=34$ ) from Wharton. We asked participants to "imagine that you are interviewing for an executive position, and as part of your visit to the company, your prospective boss takes you out to dinner. You want your prospective boss to walk away from this dinner with the impression that you are a highly intelligent person." We then asked participants to "think about how this goal might influence what you order to drink. Do you think you would look more intelligent if you ordered soda or a glass of wine?" Participants responded on a 1-11 scale. For half of the participants, 1 was labeled "I would appear much more intelligent if I order wine" and 11 was labeled "I would appear much more intelligent if I order soda." For the other half of participants, the labels were reversed. For all participants, the midpoint (6) was labeled "What I order would have no influence over how intelligent I appear."

\section{Results}

We coded responses from the two conditions so that low scores reflected a belief that ordering wine would make them appear more intelligent and high scores reflected a belief that ordering soda would make them appear more intelligent.

A significant majority of participants $(70.5 \%)$ gave a response below the midpoint $(p<.01$, sign test), suggesting that most participants thought that ordering wine would make them appear more intelligent than ordering soda.

We observe the imbibing idiot bias for wine (Appendix $\mathrm{C}$ and Study 5A), and results from this study suggest that individuals have the wrong intuition about wine's ability to enhance their perceived intelligence. Future work should explore intuitions about other types of alcoholic beverages. For example, it is possible that people are better calibrated with respect to beer.

\section{General discussion}

The relationship between alcohol consumption and cognitive impairment is so familiar that mere exposure to alcohol cues causes people to judge others as less intelligent. We observed an imbibing idiot bias for both male and female targets, for both beer and wine, and both in the absence and in the presence of evidence diagnostic of intelligence. In fact, merely exposing individuals to alcohol cues caused them to view targets who held no beverage as less intelligent.

Our findings also offer insights into the underlying process. When we explicitly asked people about the link between alcohol consumption and intelligence, most reported that alcohol consumption is not diagnostic of intelligence (Study 3). In addition, we found that the bias persists when targets did not actively choose to consume alcohol (Study 4). We even found that merely priming the concept of alcohol biased perceptions of intelligence (Study 1). Thus, a self-selection account cannot explain the imbibing idiot bias.

Instead, we propose that alcohol cues prime observers to expect cognitive impairment and that these expectations influence judgments of intelligence. In Study 4, we found that alcohol cues influenced the perceived persuasiveness of a speaker's arguments, which could be considered a proxy for perceptions of cognitive impairment, and these persuasiveness perceptions mediated the relationship between alcohol cues and judgments of overall intelligence. Future research should more directly examine our proposed process.

The imbibing idiot bias may have professional implications. Managers viewed job candidates who ordered wine during dinner as less intelligent, and therefore less hireable. However, we also found that prospective candidates have the wrong intuition about how to manage impressions of their intelligence in settings involving wine.

The intuition results from Studies 3 and 5B might appear inconsistent with the imbibing idiot bias. For example, in Study $5 \mathrm{~B}$, most participants believed that they would appear more intelligent if they order wine than if they order soda. If alcohol cues prime expectations of cognitive impairment, it is surprising that people believe that they would appear more intelligent if they order wine.

We postulate that when people are explicitly asked to consider the relationship between alcohol consumption and intelligence (as in Studies 3 and 5B), they may be unable (cf. Nisbett \& Wilson, 1977) to report how they would actually form judgments when viewing someone holding an alcoholic beverage. In fact, the disconnect is analogous to findings from Implicit Association Test (IAT) studies in which White participants explicitly disavow any prejudice toward African Americans but then implicitly reveal that very prejudice when taking an IAT (e.g., Greenwald, McGhee, \& Schwartz, 1998, p. 1475). The Study 5B results are also analogous to findings demonstrating that people often have the wrong intuition about how best to present themselves when being evaluated (e.g., Weaver, Garica, \& Schwarz, in press). People appear to have a failed mental model regarding the connection between their own alcohol consumption and their perceived intelligence. 
We observed consistent evidence of the bias across studies, but our effect sizes were modest ( $d$ s ranging from .28 to .52 ). When manipulations are minimal, however, modest effects are meaningful (Prentice \& Miller, 1992). In our studies, the manipulations were indeed quite minimal; we merely varied the type of drink targets were holding without varying cognitive performance.

Our results are also meaningful in light of lay perceptions and popular advice. Most participants in Study 5B believed that ordering wine would help them appear more intelligent. Standard advice regarding alcohol consumption in professional settings (e.g., "order one drink and nurse it all night," Capell, 2008) may also be misguided.

Future research should extend our investigation outside the lab to investigate the influence of alcohol consumption on intelligence perceptions in more naturalistic settings. Study $5 \mathrm{~A}$ examined the perceptions of observers not actually involved in the interview. Quite possibly, managers who order an alcoholic beverage during an informal interview may view candidates who avoid alcohol as lacking in social intelligence. In settings where social intelligence is highly valued, the benefits of choosing to consume alcohol may outweigh the costs.

\section{Appendix A. Sample stimuli}

Study 1

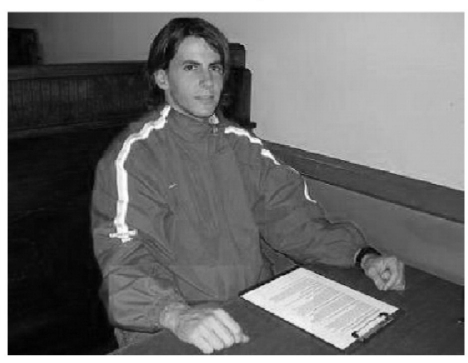

Study 2
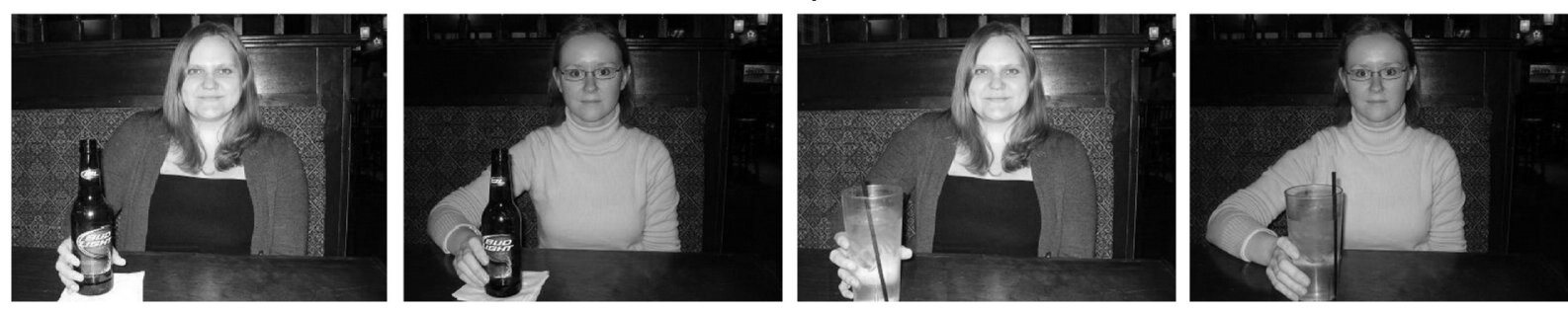

Study 4 (Video screen shots)
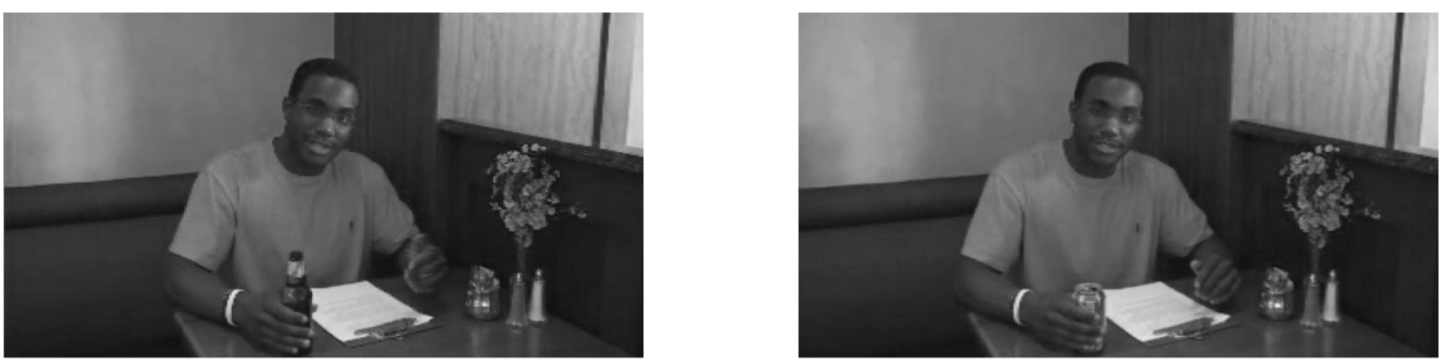

Study 5A(Sample photographs)
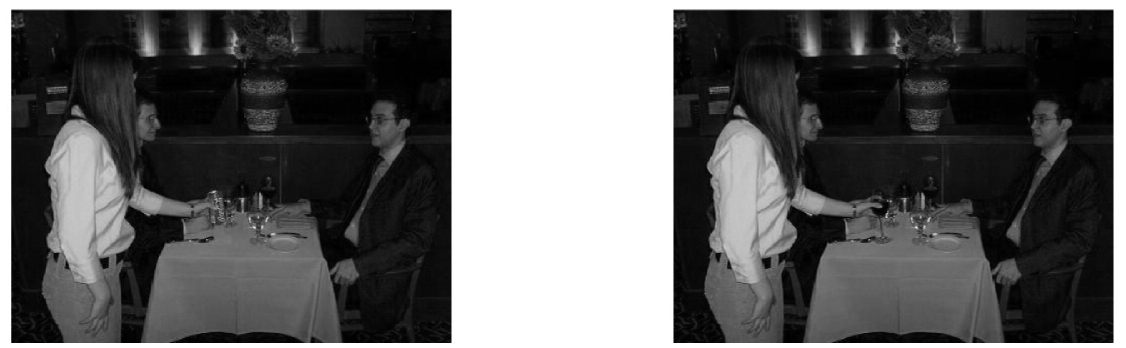


\section{Appendix B. Study 5A interview text}

\section{Screen 1}

[The job candidate is on the left. The manager is on the right.]

Manager: I hope you enjoyed your tour of the branch today and talking with some of our employees.

Candidate: I did get a good sense of the operation.

Manager: Do you feel like getting wine?

Candidate: I'm not sure. What are you having?

Manager: I'm still thinking about it, myself.

\section{Screen 2}

Waitress: Good evening, I'll be taking care of you tonight. May I start you off with something to drink? We have a nice house Merlot and a nice house Chardonnay.

Manager: I'll have [a Coke/a glass of the house Merlot].

Candidate: I'll [also] have [a Coke/a glass of the house Merlot].

Waitress: Great, thank you. I'll bring your drinks right out.

\section{Screen 3}

Manager: So, why are you leaving EGR?
Candidate: I don't think I'm valued as much as I should be at EGR. I think that my best growth opportunities are somewhere else.

Manager: If I were to ask your former supervisors to describe you, what would they say?

Candidate: Well, I'm really energetic and dependable, so I hope they would say that. I have their letters of recommendation here in my briefcase if you'd like to see them.

Manager: I try not to read too much over dinner; I can just take your word for it for now.

Candidate: Ha, of course.

\section{Screen 4}

Manager: Have you ever had a conflict with a supervisor or coworker?

Candidate: Nothing major, but there have been little incidents... little disagreements. I'm human. I try to keep the other person's perspective in mind. It's hard to do in the heat of the moment, but I try.

Manager: Well I know you've had some good experience at the junior level, but the position you're applying for now is at a more senior level. Why are you the best person for this job?

Candidate: I really learned a lot in college, and now I also have experience in the consulting field. I guess there is still a lot to learn, but I think I'm a fast learner. I should be able to hit the ground running.

\section{Appendix C. Supplemental study with target holding wine}
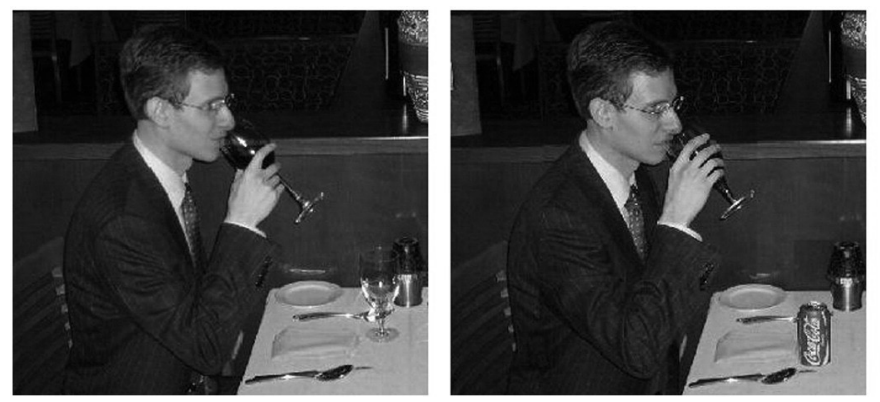

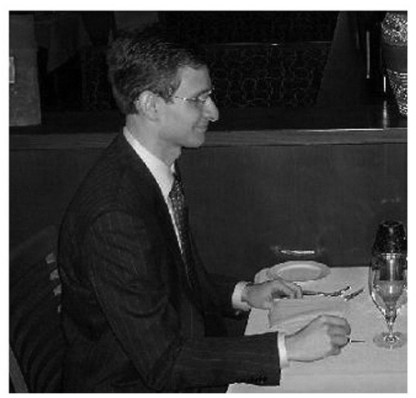

\section{Method}

We recruited 243 participants $(61 \%$ female, mean age $=37)$ via MTurk. We informed participants that they would view a photograph of a junior-level manager. We then displayed a photograph of a male in a suit and tie, drinking a glass of wine, a glass of soda (Coke), or nothing. Participants were asked "To what extent do you think this person is intelligent?" and "To what extent do you think this person is likeable?" Perceived intelligence and likeability were rated on 1-7 scales, where $1=$ not at all and $7=$ very much.
Results

Participants perceived the target to be significantly less intelligent when drinking wine $(M=5.43, S D=1.00)$ than when drinking soda $(M=5.72, S D=0.76 ; t(160)=2.03, p<.05, d=$ $.32)$ or when drinking nothing $(M=5.75, S D=0.81 ; t(160)=$ $2.24, p<.05, d=.35)$.

The type of drink targets held did not significantly influence perceived likeability: The ratings for the wine $(M=4.07, S D=$ 1.29) and soda conditions $(M=4.27, S D=1.07)$ did not differ significantly $(t(160)=1.06, p=.29)$. Both means were lower than 
the likeability mean in the no-drink condition $(M=4.83, S D=$ 1.06 ; both $p \mathrm{~s}<.01)$, likely because the target in the no-drink condition had a slight smile and a more open body position.

The results suggest that holding wine can selectively reduce perceived intelligence.

\section{References}

Bartholow, B. D., \& Heinz, A. (2006). Alcohol and aggression without consumption: Alcohol cues, aggressive thoughts, and hostile perception bias. Psychological Science, 17, 30-37.

Berger, J., \& Heath, C. (2007). Where consumers diverge from others: Identity signaling and product domains. Journal of Consumer Research, 34(2), 121-134.

Capell, P. (January 22). Is it OK to have a drink when a would-be employer is host? Wall Street Journal Retrieved from, http://online.wsj.com/article/ C51205QANDAINTERVI.html

Elias, P. K., Elias, M. F., D’Agostino, R. B., Silbershatz, H., \& Wolf, P. A. (1999). Alcohol consumption and cognitive performance in the Framingham Heart Study. American Journal of Epidemiology, 150, 580-589.

Galinsky, A., \& Schweitzer, M. (2007). Negotiators: Think before you drink. Negotiation, 10(7), 4-6. Gosling, S. D. (2008). Snoop: What your stuff says about you. New York: Basic Books.

Greenwald, A. G., McGhee, D. E., \& Schwartz, J. L. K. (1998). Measuring individual differences in implicit cognition: The Implicit Association Test. Journal of Personality and Social Psychology, 74(6), 1464-1480.
Nisbett, R. E., \& Wilson, T. D. (1977). Telling more than we can know: Verbal reports on mental processes. Psychological Review, 84(3), 231-259.

Norton, M. I., Dunn, E. W., Carney, D. R., \& Ariely, D. (2012). The persuasive "power" of stigma? Organizational Behavior and Human Decision Processes, 117(2), 261-268.

Paolacci, G., Chandler, J., \& Ipeirotis, P. G. (2010). Running experiments on Amazon Mechanical Turk. Judgment and Decision Making, 5, 411-419.

Preacher, K. J., \& Hayes, A. F. (2004). SPSS and SAS procedures for estimating indirect effects in simple mediation models. Behavior Research Methods, Instruments, and Computers, 36, 717-731.

Prentice, D. A., \& Miller, D. T. (1992). When small effects are impressive. Psychological Bulletin, 112(1), 160-164.

Schweitzer, M., \& Kerr, J. (2000). Bargaining under the influence: The role of alcohol in negotiations. Academy of Management Executive, 14(2), 47-57.

Srull, T. K., \& Wyer, R. S. (1979). The role of category accessibility in the interpretation of information about persons: Some determinants and implications. Journal of Personality and Social Psychology, 37(10), 1660-1672.

Stampfer, M. J., Kang, J. H., Chen, J., Cherry, R., \& Grodstein, F. (2005). Effects of moderate alcohol consumption on cognitive function in women. New England Journal of Medicine, 352, 245-253.

Steele, C. M., \& Josephs, R. A. (1990). Alcohol myopia: Its prized and dangerous effects. American Psychologist, 45, 921-933.

Todorov, A., Mandisodza, A. N., Goren, A., \& Hall, C. C. (2005). Inferences of competence from faces predict election outcomes. Science, 308, 1623-1626.

Weaver, K., Garica, S. M., \& Schwarz, N. in press. The presenter's paradox. Journal of Consumer Research, 39(3), forthcoming. 